\title{
Mild Ammonia Synthesis over Ba-Promoted Ru/MPC Catalysts: Effects of the Ba/Ru Ratio and the Mesoporous Structure
}

\author{
Masayasu Nishi *(D), Shih-Yuan Chen $\mathbb{D}$ and Hideyuki Takagi \\ Energy Catalyst Technology Group, Research Institute of Energy Frontier (RIEF), \\ Department of Energy and Environment, National Institute of Advanced Industrial Science \\ and Technology (AIST), 16-1 Onogawa, Tsukuba, Ibaraki 305-8589, Japan; sy-chen@aist.go.jp (S.-Y.C.); \\ hide-takagi@aist.go.jp (H.T.) \\ * Correspondence: m.nishi@aist.go.jp; Tel.: +81-29-861-8261
}

Received: 26 April 2019; Accepted: 20 May 2019; Published: 23 May 2019

\begin{abstract}
A series of novel mesoporous carbon-supported, Ba-promoted, Ru catalysts with $\mathrm{Ba} / \mathrm{Ru}$ ratios of $0.1-1.6$ and a $\mathrm{Ru}$ loading of $10 \mathrm{wt} \%$ (denoted as $0.1-1.6 \mathrm{Ba}-10 \mathrm{Ru} / \mathrm{MPC}$ ) were prepared via stepwise impregnation of $\mathrm{Ru}$ and Ba precursors on the mesoporous carbon materials. The catalysts were applied to mild ammonia synthesis and compared to reference materials, including an analog of the prepared catalyst with a $\mathrm{Ba} / \mathrm{Ru}$ ratio of 1.6 and a Ru loading of $10 \mathrm{wt} \%$ (denoted as $1.6 \mathrm{Ba}-10 \mathrm{Ru} / \mathrm{AC}$ ). Characterization by X-ray diffraction (XRD), nitrogen physisorption, and electronic microscopy revealed that the $0.1-1.6 \mathrm{Ba}-10 \mathrm{Ru} / \mathrm{MPC}$ catalysts contained Ru particles (approximately $2 \mathrm{~nm}$ ) that were well-dispersed on the mesoporous structure and nanostructured $\mathrm{Ba}\left(\mathrm{NO}_{3}\right)_{2}$ species. These species decomposed into amorphous $\mathrm{BaO}_{x}$ species, acting as a promoter on the metallic Ru particles forming catalytically active sites for ammonia synthesis. All the 0.1-1.6Ba-10Ru/MPC catalysts showed a synergistic effect of the active Ba and Ru species, which were stabilized in the mesoporous carbon framework with fast molecular diffusion and could effectively catalyze mild ammonia synthesis (280-450 ${ }^{\circ} \mathrm{C}$ and $0.99 \mathrm{MPa}$ ) even under intermittently variable conditions, particularly for those with $\mathrm{Ba} / \mathrm{Ru}$ ratios of $>0.5$. In contrast, the $1.6 \mathrm{Ba}-10 \mathrm{Ru} / \mathrm{AC}$ analog showed poor activity and stability for ammonia synthesis due to the sintering of $\mathrm{Ba}$ and Ru particles on the outer surface of the microporous carbon framework, resulting in low molecular diffusion and weak synergistic effect of the catalytically active sites.
\end{abstract}

Keywords: ammonia synthesis; ruthenium; barium; porous carbons; sustainable hydrogen

\section{Introduction}

The atmospheric $\mathrm{CO}_{2}$ concentration has rapidly increased over the past two decades due to the burning of fossil fuels, causing increases in global temperature, sea level, and extreme climate [1]. As part of the adoption of the Paris Agreement, the Japanese government has set a goal to cut $26 \%$ and $80 \%$ of national $\mathrm{CO}_{2}$ emissions by 2030 and 2050, respectively, based on the data recorded in 2013 [2]. To achieve this goal, hydrogen is a promising energy source with clean emissions, particularly for hydrogen produced by water electrolysis using renewable energy [3]. However, hydrogen is flammable, expensive, and hard to liquify, rendering its storage, transportation, and utilization quite difficult. The conversion of hydrogen to various chemicals, so-called "hydrogen carriers", is a potential method to store, transport, and use hydrogen energy more safely [4]. For instance, ammonia $\left(\mathrm{NH}_{3}\right)$ is composed of one nitrogen and three hydrogen atoms, corresponding to $17.6 \mathrm{wt} \%$ hydrogen and its industry is experienced including well-developed infrastructure for production, transportation, storage, 
and application. Recent studies have demonstrated that ammonia can be burned with fossil fuel to generate electricity with reduced $\mathrm{CO}_{2}$ emissions [5]. However, ammonia is industrially synthesized by the Haber-Bosch process using a $\mathrm{Fe}_{2} \mathrm{O}_{3}-\mathrm{Al}_{2} \mathrm{O}_{3}-\mathrm{K}_{2} \mathrm{O}$ catalyst under severe conditions $\left(>450{ }^{\circ} \mathrm{C}\right.$ and $20 \mathrm{MPa}$ ), which accounts for ca. $1 \%$ of world energy requirements and produces a large amount of $\mathrm{CO}_{2}$ (1.2 ton- $\mathrm{CO}_{2} /$ ton- $-\mathrm{NH}_{3}$ ) [6-8]. Recent studies have been conducted on energy-efficient and environment-friendly ammonia synthesis over novel multifunctional catalysts [9-11]. For example, Ru-based catalysts are able to synthesize green ammonia under mild conditions using $\mathrm{CO}_{2}$-free hydrogen generated from water electrolysis using renewable energy [12]. It should be noted that unpromoted Ru-based catalysts exhibit low activity in ammonia synthesis under mild conditions, whereas that the reverse is true for those containing promotors, such as Ba and Cs [13-16], or supported on novel materials, such as $12 \mathrm{CaO} \cdot 7 \mathrm{Al}_{2} \mathrm{O}_{3}, \mathrm{Ca}\left(\mathrm{NH}_{2}\right), \mathrm{Pr}_{2} \mathrm{O}_{3}$, and carbon [13,17-19]. This is primarily due to the enhanced electronic and structural properties of $\mathrm{Ru}$ active sites, which can activate the nitrogen molecule under mild conditions [20]. Because renewable energy is intermittently available, recent studies have focused on the development of next-generation Ru-based catalysts with improved activity and stability, which adhere to the principles of green synthesis for ammonia [21].

Carbon has been widely applied in industry for catalysis, adsorption, and electronic devices [22-24]. The pioneering works by Aika et al. demonstrated that ammonia synthesis over a carbon-supported Ru catalyst with alkali and alkaline earth elements added as promotors could be performed at a relatively low temperature and pressure $\left(<400{ }^{\circ} \mathrm{C},<0.1 \mathrm{MPa}\right)[25,26]$. However, the carbon-supported Ru catalysts were unstable during ammonia synthesis and became deactivated due to the methanation of carbon by dissociated hydrogen near the Ru active sites. Recently, it was shown that Cs-promoted Ru supported on activated carbon exhibited low activity for ammonia synthesis, [21] likely due to the Ru particle aggregation caused by methanation during ammonia synthesis. On the other hand, the promotion effect of the Ba species on the carbon-supported Ru catalysts for mild ammonia synthesis has been reported [27-29]. Rossetti et al. suggested that the barium oxide $(\mathrm{BaO})$ was formed in the carbon-supported Ru catalysts and acted as an electronic promoter for ammonia synthesis [27,28]. Hansen et al. reported that formation of the $\mathrm{B}_{5}$ sites (i.e., steps) on the Ru surface are promoted by the $\mathrm{BaO}_{x}$ species via electrostatic interaction and facilitate $\mathrm{N}_{2}$ dissociation [29]. Other studies argued that the Ba species acts as a structural promotor to create highly active sites on the Ru particles supported by carbon for ammonia synthesis [30,31]. The preparation of carbon-supported Ru catalysts with added promotors, which can efficiently and stably catalyze mild ammonia synthesis at a low temperature and pressure must be further investigated. In this research, we developed a series of novel mesoporous carbon-supported and Ba-promoted Ru catalysts for mild ammonia synthesis compared to several reference catalysts. The effects of the Ba promotor and mesoporous structure on the activity and stability of the Ba-promoted Ru/MPC catalysts were examined. The potential application of the 1.6Ba-10Ru-MPC catalyst for intermittent ammonia synthesis was reported for the first time.

\section{Results and Discussion}

\subsection{Characterizations}

Figure 1 shows the wide-angle XRD pattern of the prepared 1.6Ba-10Ru/MPC compared to those of the reference samples. The 1.6Ba-10Ru/MPC sample showed two sets of X-ray diffraction peaks and no signal arising from $\mathrm{Ru}$ was observed, suggesting that $\mathrm{Ru}$ is too small to be examined by XRD. A set of different peaks at 18.9, 21.8, 31.1, 36.6, 38.4, and 50.1 ${ }^{\circ}$ are associated with the (111), (200), (220), (311), (222), (331), and (420) planes of $\mathrm{Ba}\left(\mathrm{NO}_{3}\right)_{2}$ (PDF card number: 3424; precursor). The $\mathrm{Ba}\left(\mathrm{NO}_{3}\right)_{2}$ particle size was estimated using the Scherrer equation as $49 \mathrm{~nm}$. The diffraction peaks of $\mathrm{Ba}\left(\mathrm{NO}_{3}\right)_{2}$ with crystallite sizes ranging from 29 to $76 \mathrm{~nm}$ were observed for the $0.5-1.6 \mathrm{Ba}-10 \mathrm{Ru} / \mathrm{MPC}$, 1.6Ba/MPC, and 1.6Ba-10Ru/AC samples (Table 1). This indicates that Ba easily forms large particles in the microporous 1.6Ba-10Ru/AC samples. In addition to the decreased $\mathrm{Ba}$ size as a function of $\mathrm{Ba}$ 
loading, the decreased Ba size in the 1.6Ba/MPC and 0.5-1.6Ba-10Ru/MPC samples indicates that the mesoporous structure of MPC is a suitable support for impregnation of Ba species. In addition, the $\mathrm{Ba}$ sizes of the $1 \mathrm{Ba}-10 \mathrm{Ru} / \mathrm{MPC}$ and $1.6 \mathrm{Ba}-10 \mathrm{Ru} / \mathrm{MPC}$ catalysts were smaller than that of $1.6 \mathrm{Ba} / \mathrm{MPC}$, indicating that improved $\mathrm{Ba}$ dispersion can be obtained due to strong interaction of the $\mathrm{Ba}$ and $\mathrm{Ru}$ species. The diffraction peaks of Ba were hardly observed for the $0.1 \mathrm{Ba}-10 \mathrm{Ru} / \mathrm{MPC}$ sample, implying that $\mathrm{Ba}$ was present in the form of semi-crystalline species at low Ba loadings. It should be noted that 1.6Ba-10Ru/MPC and the reference samples showed no Ru diffraction peaks, suggesting that Ru was finely dispersed in the MPC support with low or no crystallinity. The other set of diffraction peaks observed at 26.4 and $42.6^{\circ}$ are associated with the (002) and (100) planes of the graphite originally present in the MPC support. However, the graphite feature of MPC was slightly weakened after impregnation of $\mathrm{Ba}$ and $\mathrm{Ru}$.

Table 1. The structural properties of the prepared Ba-Ru catalysts and reference materials.

\begin{tabular}{|c|c|c|c|c|c|c|c|c|c|}
\hline \multirow{2}{*}{ Samples } & \multirow{2}{*}{$\begin{array}{c}S_{\mathrm{BET}} \\
\left(\mathrm{m}^{2} \mathrm{~g}^{-1}\right)\end{array}$} & \multirow{2}{*}{$\begin{array}{c}V_{\text {Total }} \\
\left(\mathrm{cm}^{3} \mathrm{~g}^{-1}\right)\end{array}$} & \multirow{2}{*}{$\underset{\left(\mathrm{cm}^{3} \mathrm{~g}^{-1}\right)^{1}}{V_{\text {icro }}}$} & \multirow{2}{*}{$\begin{array}{c}V_{\text {Meso }} \\
\left(\mathrm{cm}^{3} \mathrm{~g}^{-1}\right)^{2}\end{array}$} & \multirow{2}{*}{$\begin{array}{c}\text { Pore Size } \\
\qquad(\mathrm{nm})^{3}\end{array}$} & \multirow{2}{*}{$\begin{array}{c}\begin{array}{c}\text { Ba Size } \\
(\mathrm{nm})\end{array}\end{array}$} & \multicolumn{2}{|c|}{ Ru Size (nm) } & \multirow{2}{*}{$\begin{array}{c}\text { CO Uptake } \\
\left(\mathrm{cm}^{3} \mathrm{~g}^{-1}\right)\end{array}$} \\
\hline & & & & & & & HRTEM $^{4}$ & CO Chem ${ }^{5}$ & \\
\hline 1.6Ba-10Ru/MPC & 685 & 1.65 & 0.29 & 1.36 & 5.8 & 49 & $1.8 \pm 0.3$ & $11.3(8 \%)$ & 1.8 \\
\hline 1Ba-10Ru/MPC & 802 & 1.83 & 0.32 & 1.51 & 5.8 & 42 & $1.8 \pm 0.6$ & $8.0(12 \%)$ & 2.6 \\
\hline $0.5 \mathrm{Ba}-10 \mathrm{Ru} / \mathrm{MPC}$ & 865 & 1.93 & 0.35 & 1.58 & 5.8 & 29 & $1.8 \pm 0.4$ & $2.9(32 \%)$ & 7.2 \\
\hline $0.1 \mathrm{Ba}-10 \mathrm{Ru} / \mathrm{MPC}$ & 1083 & 2.27 & 0.44 & 1.83 & 5.4 & n.d. & $1.7 \pm 0.4$ & $2.0(46 \%)$ & 10.3 \\
\hline 10Ru/MPC & 1155 & 2.36 & 0.46 & 1.90 & 5.4 & - & $1.8 \pm 0.5$ & $2.2(42 \%)$ & 9.4 \\
\hline 1.6Ba/MPC & 726 & 1.70 & 0.31 & 1.39 & 5.8 & 60 & - & - & 0.7 \\
\hline 1.6Ba-10Ru/AC & 710 & 0.38 & 0.29 & 0.09 & 0.8 & 76 & $1.2 \pm 0.2$ & $6.4(14 \%)$ & 3.2 \\
\hline
\end{tabular}

${ }^{1}$ Microporous pore volume $\left(\mathrm{V}_{\text {Micro }}\right)$ was calculated using the Dubinin-Astakhov (DA) plot and $\alpha_{\mathrm{s}}$-plot method. ${ }^{2}$ Mesoporous pore volume $\left(\mathrm{V}_{\text {Meso }}\right)$ was calculated as $\mathrm{V}_{\text {Total }}-\mathrm{V}_{\text {Micro }}{ }^{3}$ Pore sizes determined at the peak maxima of the non-linear density function theory (NLDFT) calculation. ${ }^{4}$ Determined from the high-resolution transmission electron microscopy (HRTEM) images. ${ }^{5}$ Determined from CO chemisorption. The data in the parentheses are the $\mathrm{Ru}$ dispersions calculated by CO chemisorption.

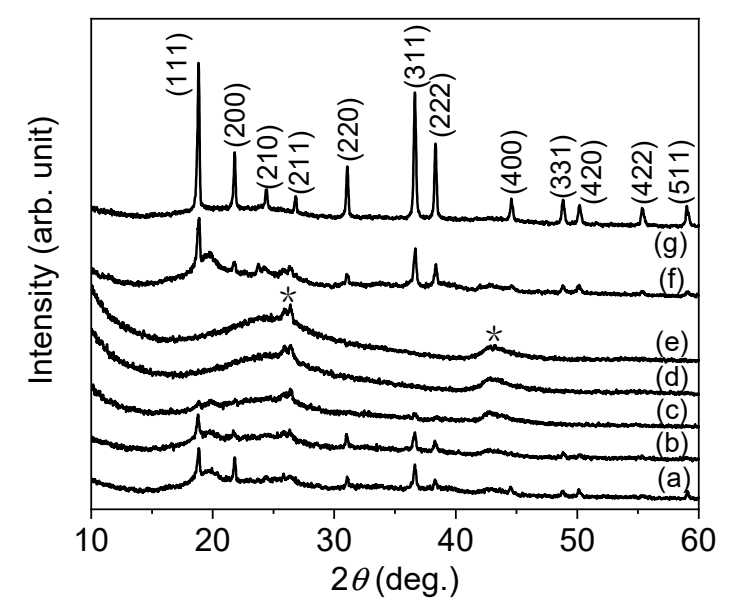

Figure 1. Wide-angle $\mathrm{XRD}$ patterns of the prepared $\mathrm{Ba}-\mathrm{Ru}$ catalysts and reference materials-(a) 1.6Ba-10Ru/MPC, (b) 1Ba-10Ru/MPC, (c) 0.5Ba-10Ru/MPC, (d) 0.1Ba-10Ru/MPC, (e) 10Ru/MPC, (f) $1.6 \mathrm{Ba} / \mathrm{MPC}$, and (g) $1.6 \mathrm{Ba}-10 \mathrm{Ru} / \mathrm{AC}$. The "asterisk" peaks denote those associated with the carbon materials.

Figure 2 shows the $\mathrm{N}_{2}$ adsorption-desorption isotherms and NLDFT pore size distributions of the prepared 1.6Ba-10Ru/MPC sample compared to those of the reference samples. The $\mathrm{N}_{2}$ adsorption-desorption isotherms can be divided into two groups: the classical type IV isotherm with an $\mathrm{H}_{1}$ hysteresis loop for 1.6Ba/MPC, 10Ru/MPC, and 0.1-1.6Ba-10Ru/MPC, which is associated with characteristic features of the MPC with mesoporous structure. The $\mathrm{H}_{1}$ hysteresis loop is slightly shifted to the lower $\mathrm{P} / \mathrm{P}_{0}$ region by impregnation of $\mathrm{Ru}$ and $\mathrm{Ba}$, and its intensity decreased. This indicates that the $\mathrm{Ru}$ and Ba species are impregnated inside the mesopores of MPC. The other group can be classified as a typical type I isotherm with no apparent hysteresis loop (1.6Ba-10Ru/AC). It is evident that the 1.6Ba-10Ru/AC sample only contained a microporous structure. Table 1 lists the structural properties of the prepared 1.6Ba-10Ru/MPC sample, in comparison with reference samples. 

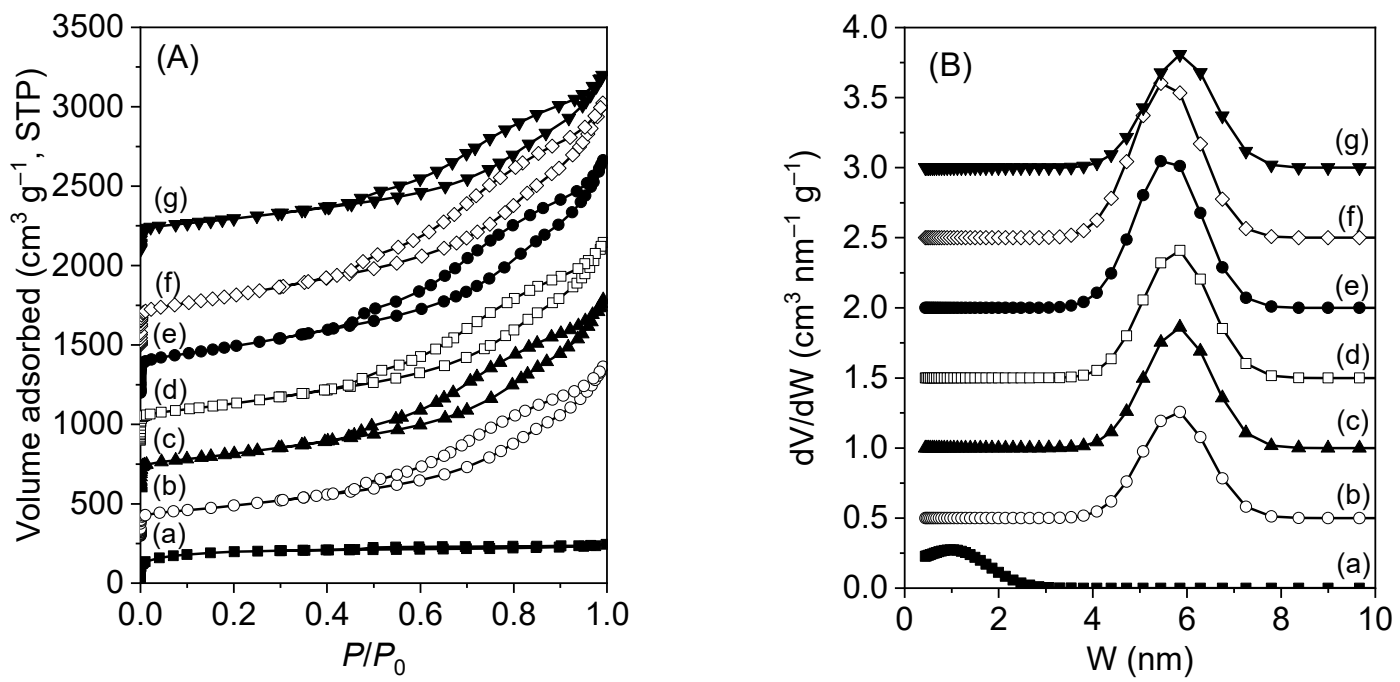

Figure 2. (A) $\mathrm{N}_{2}$ adsorption-desorption isotherms and (B) NLDFT pore size distributions of the prepared Ba-Ru catalysts and reference materials: (a) 1.6Ba-10Ru/AC, (b) $1.6 \mathrm{Ba}-10 \mathrm{Ru} / \mathrm{MPC}$, (c) $1 \mathrm{Ba}-10 \mathrm{Ru} / \mathrm{MPC}$, (d) $0.5 \mathrm{Ba}-10 \mathrm{Ru} / \mathrm{MPC}$, (e) $0.1 \mathrm{Ba}-10 \mathrm{Ru} / \mathrm{MPC}$, (f) $10 \mathrm{Ru} / \mathrm{MPC}$, and (g) $1.6 \mathrm{Ba} / \mathrm{MPC}$.

The specific surface area $\left(\mathrm{S}_{\mathrm{BET}}\right)$ of $1.6 \mathrm{Ba}-10 \mathrm{Ru} / \mathrm{MPC}$ was similar to that of $1.6 \mathrm{Ba}-10 \mathrm{Ru} / \mathrm{AC}$, whereas 1.6Ba-10Ru/MPC exhibited higher total pore $\left(\mathrm{V}_{\text {Total }}\right)$ and mesopore volumes $\left(\mathrm{V}_{\text {Meso }}\right)$ than those of $1.6 \mathrm{Ba}-10 \mathrm{Ru} / \mathrm{AC}$, which contained a large micropore volume $\left(\mathrm{V}_{\mathrm{Micro}}\right)$. The pore size analysis was calculated using the desorption branch via the non-linear density function theory (NLDFT) method and slit-pore model. The pore size of $1.6 \mathrm{Ba}-10 \mathrm{Ru} / \mathrm{MPC}$ was determined to be approximately 5-6 nm, which is much larger than that of $1.6 \mathrm{Ba}-10 \mathrm{Ru} / \mathrm{AC}$. Similar results were observed for $1.6 \mathrm{Ba} / \mathrm{MPC}$, $10 \mathrm{Ru} / \mathrm{MPC}$ and $0.1-1 \mathrm{Ba}-10 \mathrm{Ru} / \mathrm{MPC}$. Thus, the MPC-supported Ru catalysts with and without $\mathrm{Ba}$ promoter are large-pore mesoporous materials and 1.6Ba-10Ru/AC is a microporous material.

The microstructure and particle size distributions of the 1.6Ba-10Ru/MPC and reference samples were carefully examined by high-resolution transmission electron microscopy (HRTEM) and high-angle annular dark field scanning transmission microscopy (HAADF-STEM). The related HRTEM images are shown in Figure 3 and Figure S1. The Ru size distributions and HAADF-STEM images are shown in Figures S2 and S3, respectively. The Ru nanoparticles of the 10Ru/MPC and 0.1-1.6Ba-10Ru/MPC catalysts were clearly observed on the mesoporous carbon framework and their sizes were approximately $1.8 \mathrm{~nm}$, regardless of Ba loading. The Ru nanoparticles of the 1.6Ba-10Ru/AC catalyst also contained small Ru particles approximately $1.2 \mathrm{~nm}$ in size and apparently larger than the micropores (ca. $0.8 \mathrm{~nm}$ ) of the AC support. This suggests that the Ru nanoparticles in 1.6Ba-10Ru/AC should be impregnated on the pore mouths of the AC microporous material. The HRTEM images with EDX mapping show that large Ba particles in the nanometer scale (approximately several tens of nm) aggregated on the prepared catalysts (Figure S3), which is presumably associated with the $\mathrm{Ba}\left(\mathrm{NO}_{3}\right)_{2}$ particles observed in the XRD pattern (Figure 1). These $\mathrm{Ba}\left(\mathrm{NO}_{3}\right)_{2}$ particles were converted into active $\mathrm{BaO}_{x}$ species on the $\mathrm{Ru}$ particles for ammonia synthesis, which will be discussed in detail in Section 2.2.

The influences of the Ba promoter and porous structure on the Ru size and chemical environment of the prepared Ba-Ru catalysts were further investigated by $\mathrm{CO}$ chemisorption. All samples were reduced at $450{ }^{\circ} \mathrm{C}$ for $2 \mathrm{~h}$ under a $\mathrm{H}_{2}$ flow $\left(50 \mathrm{~mL} \mathrm{~min}^{-1}\right.$ ) before $\mathrm{CO}$ chemisorption. Table 1 shows that the Ru particle sizes of 10Ru/MPC and 0.1-1.6Ba-10Ru/MPC were 2-11 nm, which increased with increasing Ba loading and were much bigger than those determined by the HRTEM images, especially for the $0.5-1.6 \mathrm{Ba}-10 \mathrm{Ru} / \mathrm{MPC}$ catalysts. Similar results were observed for the $1.6 \mathrm{Ba}-10 \mathrm{Ru} / \mathrm{AC}$ catalyst. The Ru particle sizes of the prepared Ba-Ru catalysts were overestimated by the $\mathrm{CO}$ chemisorption method, likely due to that the covering of Ba species on the Ru surfaces of the prepared Ba-Ru catalysts, especially for the $0.5-1.6 \mathrm{Ba}-10 \mathrm{Ru} / \mathrm{MPC}$ catalysts. Therefore, the adsorption of $\mathrm{CO}$ on the Ru surfaces was hindered, leading to the overestimation of Ru sizes. 

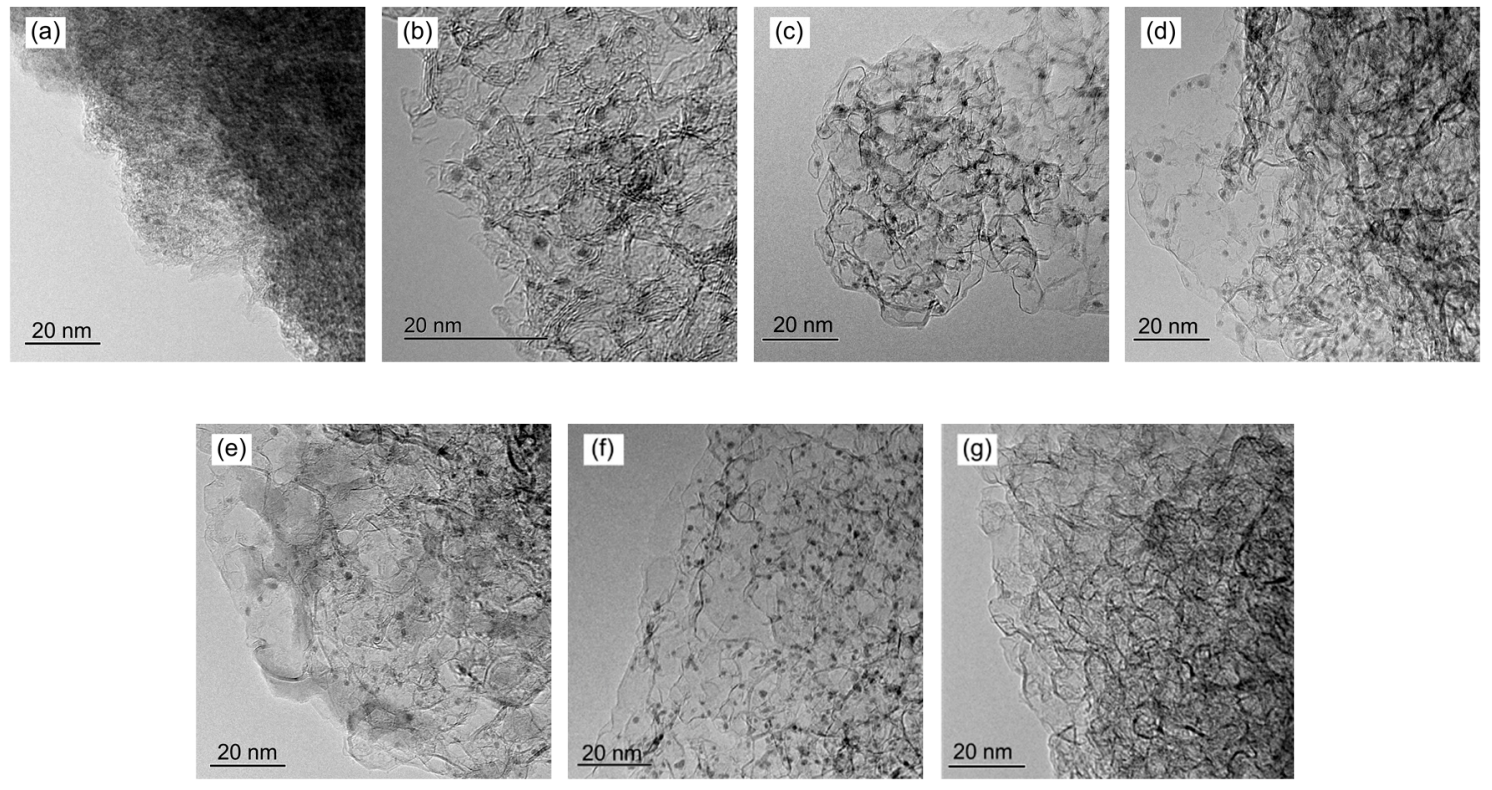

Figure 3. HRTEM images of the prepared Ba-Ru catalysts and reference materials: (a) 1.6Ba-10Ru/AC, (b) $1.6 \mathrm{Ba}-10 \mathrm{Ru} / \mathrm{MPC}$, (c) $1 \mathrm{Ba}-10 \mathrm{Ru} / \mathrm{MPC}$, (d) $0.5 \mathrm{Ba}-10 \mathrm{Ru} / \mathrm{MPC}$, (e) $0.1 \mathrm{Ba}-10 \mathrm{Ru} / \mathrm{MPC}$, (f) $10 \mathrm{Ru} / \mathrm{MPC}$, and $(\mathrm{g}) 1.6 \mathrm{Ba} / \mathrm{MPC}$.

\subsection{Mild Ammonia Synthesis}

The catalytic performance of the $0.1-1.6 \mathrm{Ba}-10 \mathrm{Ru} / \mathrm{MPC}$ samples as solid catalysts for ammonia synthesis was examined in a stainless-steel fixed-bed reactor with a quartz inlet under mild conditions (280-450 ${ }^{\circ} \mathrm{C}$ and $0.99 \mathrm{MPa}$ ) and compared to reference samples. After the reaction, the downstream gas was analyzed using an online gas chromatography instrument equipped a thermal conductivity detector (GC-TCD) using a Thermon-3000 + KOH $(2+2) \%$ Sunpak-N 60/100 mesh column. The space velocity (SV) was maintained at $9000 \mathrm{~h}^{-1}$ and the standard G1-grade gas of $\mathrm{H}_{2}$ and $\mathrm{N}_{2}$ was used as a feedstock and the $\mathrm{H}_{2} / \mathrm{N}_{2}$ ratio was kept at 3. Prior to ammonia synthesis, the samples were reduced at $450{ }^{\circ} \mathrm{C}$ for $2 \mathrm{~h}$ using a pure $\mathrm{H}_{2}$ flow with an SV value of $10000 \mathrm{~h}^{-1}$. The ammonia synthesis activity was calculated by dividing the synthesized amount per unit time by the catalyst mass $\left(\mathrm{mmol} \mathrm{g}^{-1} \mathrm{~h}^{-1}\right)$. Figure 4 shows the ammonia synthesis activity as a function of reaction temperature over the $0.1-1.6 \mathrm{Ba}-10 \mathrm{Ru} / \mathrm{MPC}$ catalysts in comparison to those of the $10 \mathrm{Ru} / \mathrm{MPC}$, $1.6 \mathrm{Ba} / \mathrm{MPC}$, and $1.6 \mathrm{Ba}-10 \mathrm{Ru} / \mathrm{AC}$ catalysts. A volcano-shaped curve with a maximum activity of approximately $10 \mathrm{mmol} \mathrm{g}^{-1} \mathrm{~h}^{-1}$ at $380{ }^{\circ} \mathrm{C}$ was observed for the $0.5-1.6 \mathrm{Ba}-10 \mathrm{Ru} / \mathrm{MPC}$ catalysts, corresponding to the equilibrium of ammonia formation and decomposition reactions (Table 2).

Similar results were observed for the $0.1 \mathrm{Ba}-10 \mathrm{Ru} / \mathrm{MPC}$ catalyst, although ammonia synthesis activity decreased and its maximum number was observed in the higher temperature region. Compared to the $0.5-1.6 \mathrm{Ba} / 10 \mathrm{Ru} / \mathrm{MPC}$ catalysts, the $1.6 \mathrm{Ba}-10 \mathrm{Ru} / \mathrm{AC}$ catalyst showed only $1 / 4$ activity for ammonia synthesis and the $10 \mathrm{Ru} / \mathrm{MPC}$ catalyst was only active when the reaction temperature was $>470{ }^{\circ} \mathrm{C}$. The 1.6Ba/MPC sample was completely inactive for ammonia synthesis under the mild reaction conditions. These observations indicate that the $\mathrm{Ba} / \mathrm{Ru}$ molar ratio should be $>0.5$ for the $\mathrm{Ba}-10 \mathrm{Ru} / \mathrm{MPC}$ catalysts and that the mesoporous carbon framework can significantly facilitate ammonia synthesis. The turnover frequency (TOF) was calculated by dividing the ammonia synthesis rate by the number of surface $\mathrm{Ru}$ atoms estimated from CO chemisorption. The TOF values of the $0.1-1.6 \mathrm{Ba}-10 \mathrm{Ru} / \mathrm{MPC}$ catalysts were positively correlated with the $\mathrm{Ba} / \mathrm{Ru}$ molar ratio due to the formation of $\mathrm{B}_{5}$ sites on the $\mathrm{Ru}$ surfaces [30,31]. Among the prepared Ba-Ru catalysts, 1.6Ba-10Ru/MPC showed a high rate of ammonia synthesis per Ru species and higher TOF than its counterparts and reference catalysts. The Ru and Ba species were homogeneously dispersed in the nanospace of the MPC support, resulting in a synergistic effect and high ammonia synthesis activity. It should be noted that the 1.6Ba-10Ru/MPC catalyst, 
with proper amounts of $\mathrm{Ba}$ and $\mathrm{Ru}$, is superior to the previously developed catalyst $2.5 \mathrm{Cs}-10 \mathrm{Ru} / \mathrm{MPC}$ with similar Cs and Ru contents synthesized using the same method. Thus, it is clear that Ba assists $\mathrm{Ru}$-catalyzed ammonia synthesis, probably due to the electronic and structural promotion effects that create more $B_{5}$ sites on the Ru surfaces.

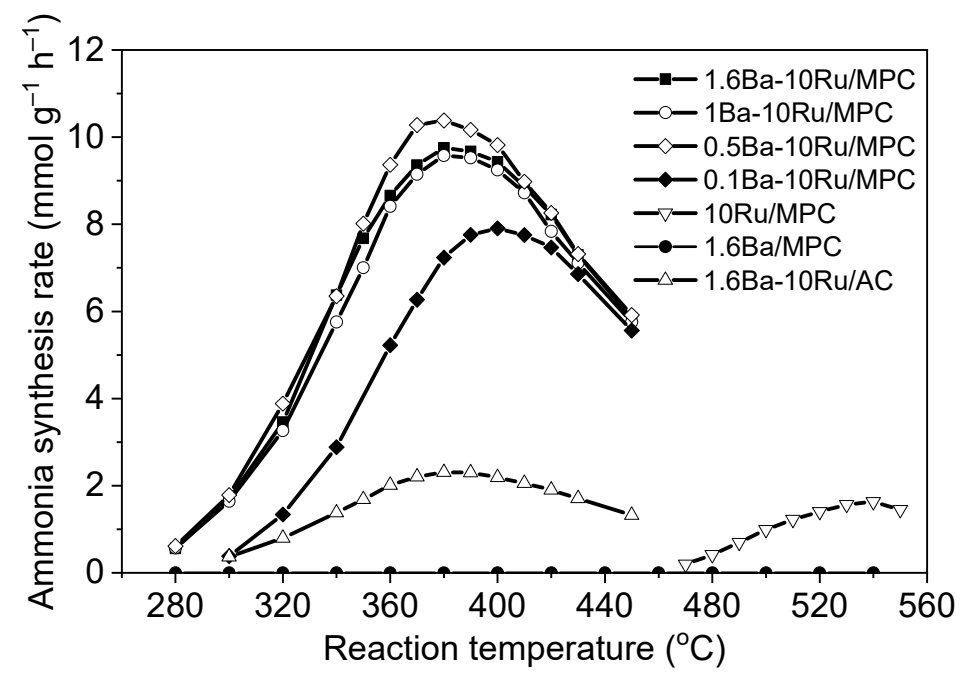

Figure 4. Rate of ammonia synthesis as a function of reaction temperature over the $0.1-1.6 \mathrm{Ba}-10 \mathrm{Ru} / \mathrm{MPC}$ and reference catalysts.

Table 2. Catalytic performance of the prepared Ba-Ru catalysts and reference materials for ammonia synthesis.

\begin{tabular}{|c|c|c|c|c|c|}
\hline Samples & $\begin{array}{c}\text { Ba/Ru } \\
\text { Molar Ratio }\end{array}$ & $\begin{array}{l}\text { Temp. } \\
\left({ }^{\circ} \mathrm{C}\right)^{1}\end{array}$ & $\begin{array}{c}\text { Rate } \\
\left(\mathrm{mmol} \mathrm{g}_{\mathrm{Ru}}{ }^{-1} \mathrm{~h}^{-1}\right)^{1}\end{array}$ & $\begin{array}{c}\text { Rate } \\
\left(\mathrm{mmol} \mathrm{g}_{\text {cat }}^{-1} \mathrm{~h}^{-1}\right)^{1}\end{array}$ & $\begin{array}{l}\text { TOF } \\
\left(h^{-1}\right)\end{array}$ \\
\hline 1.6Ba-10Ru/MPC & 1.6 & 380 & 148 & 9.8 & 186 \\
\hline 1Ba-10Ru/MPC & 1 & 380 & 130 & 9.6 & 109 \\
\hline $0.5 \mathrm{Ba}-10 \mathrm{Ru} / \mathrm{MPC}$ & 0.5 & 380 & 128 & 10.4 & 40 \\
\hline $0.1 \mathrm{Ba}-10 \mathrm{Ru} / \mathrm{MPC}$ & 0.1 & 400 & 89 & 7.9 & 20 \\
\hline 10Ru/MPC & 0 & 540 & 18 & 1.6 & 4 \\
\hline 1.6Ba/MPC & - & - & 0 & 0 & 0 \\
\hline 1.6Ba-10Ru/AC & 1.6 & 380 & 35 & 2.3 & 25 \\
\hline 2.5Cs-10Ru/MPC & $2.5^{2}$ & 370 & 122 & 8.1 & 17 \\
\hline
\end{tabular}

${ }^{1}$ The maximum ammonia synthesis rate was observed from the curves in Figure 4 and corresponding reaction temperature. ${ }^{2}$ The $\mathrm{Cs} / \mathrm{Ru}$ molar ratio was referred to our recent study [32].

The microstructure and particle size distribution of the used Ba-Ru catalysts were examined by XRD and HRTEM and compared to those of fresh catalysts (Figures 5 and 6). The used 0.1-1.6Ba-10Ru/MPC catalysts exhibited weak diffraction peaks at $2 \theta=26.4$ and $42.6^{\circ}$, corresponding to the graphite structure of MPC, and several weak diffraction peaks arising from the around $6 \mathrm{~nm} \mathrm{BaCO}$ particles. The mesoporous carbon framework with small graphite character was unaffected by the ammonia synthesis conditions. $\mathrm{BaCO}_{3}$ was presumably formed by the reaction of $\mathrm{BaO}$ or $\mathrm{Ba}(\mathrm{OH})_{2}$ species, which are typically formed by decomposition of the $\mathrm{Ba}\left(\mathrm{NO}_{3}\right)_{2}$ precursor and reaction with atmospheric $\mathrm{CO}_{2}$ molecules when the used 0.1-1.6Ba-10Ru/MPC catalysts were exposed to air. The HRTEM image shows that the Ru size $(2.1 \pm 0.9 \mathrm{~nm})$ and mesoporous carbon framework of the used 1.6Ba-10Ru/MPC catalyst resembled those of the fresh 1.6Ba-10Ru/MPC catalyst. The HRTEM-mapping shows that the distributions of $\mathrm{Ru}$ and $\mathrm{Ba}$ over the $0.1-1.6 \mathrm{Ba}-10 \mathrm{Ru} / \mathrm{MPC}$ catalysts were largely unchanged after ammonia synthesis. In contrast, the XRD and HRTEM results clearly show that the used 1.6Ba-10Ru/AC catalyst contained large $\mathrm{BaCO}_{3}$ and $\mathrm{Ru}^{0}$ particles with crystallite and particle sizes of ca. 13 and $4.2 \pm 2.0 \mathrm{~nm}$, respectively. The used 1.6Ba/MPC sample exhibited strong diffraction peaks associated with large $\mathrm{BaCO}_{3}$ particles formed by the decomposition of $\mathrm{Ba}\left(\mathrm{NO}_{3}\right)_{2}$ to large 
$\mathrm{BaO}$ and $\mathrm{Ba}(\mathrm{OH})_{2}$ species, and subsequent reaction of these $\mathrm{BaO}_{\mathrm{x}}$ species with atmospheric $\mathrm{CO}_{2}$. This observation indicates that highly-dispersed, small $\mathrm{BaO}_{x}$ particle-promoted metallic $\mathrm{Ru}$ species can be formed in the 0.1-1.6Ba-10Ru/MPC catalysts during ammonia synthesis, whereas the reverse is true for the $1.6 \mathrm{Ba} / \mathrm{MPC}$ and $1.6 \mathrm{Ba}-10 \mathrm{Ru} / \mathrm{AC}$ catalysts. Combining the XRD and HRTEM results with the aforementioned characterization and catalytic studies, the $\mathrm{Ba}\left(\mathrm{NO}_{3}\right)_{2}$ precursor is transformed into amorphous $\mathrm{BaO}$ or $\mathrm{Ba}(\mathrm{OH})_{2}$ species in the $0.1-1.6 \mathrm{Ba}-10 \mathrm{Ru} / \mathrm{MPC}$ catalysts under the ammonia synthesis reaction conditions. These amorphous $\mathrm{BaO}$ or $\mathrm{Ba}(\mathrm{OH})_{2}$ species act as efficient promoters for Ru-catalyzed ammonia synthesis, where the catalytically active sites are the well-dispersed $\mathrm{Ru}$ particles stacked with activated $\mathrm{BaO}_{x}$ species at the nanoscale. These conclusions are particularly supported by the $\mathrm{CO}$ chemisorption data. In the $1.6 \mathrm{Ba}-10 \mathrm{Ru} / \mathrm{AC}$ catalyst, $\mathrm{Ba}\left(\mathrm{NO}_{3}\right)_{2}$, which is probably inhomogeneously impregnated on the AC support, should exhibit low interaction with the Ru species. Both $\mathrm{Ba}$ and Ru aggregate easily on the AC support during ammonia synthesis resulting in the low activity of the 1.6Ba-10Ru/AC catalyst for ammonia synthesis. The stability and durability of the 1.6Ba-10Ru/MPC catalyst were surveyed by intermittently variable ammonia synthesis, continuously operated in a fixed-bed reaction system under a $\mathrm{H}_{2}$ pressure of $0.99 \mathrm{MPa}$ for $>70 \mathrm{~h}$, where the reaction temperatures and SV values varied between $300-380{ }^{\circ} \mathrm{C}$ and $9000-18000 \mathrm{~h}^{-1}$, respectively. Figure 7 shows that the ammonia synthesis rate over the 1.6Ba-10Ru/MPC catalyst decreased with decreasing reaction temperature and SV. However, 1.6Ba-10Ru/MPC catalyzed intermittently variable ammonia synthesis at each stage with high stability, indicating that the ammonia synthesis activity can be finely and reversibly adjusted by the reaction parameters. This also indicates that the $1.6 \mathrm{Ba}-10 \mathrm{Ru} / \mathrm{MPC}$ catalyst has potential application for intermittently variable ammonia synthesis under mild conditions, where its activity can be quickly adjusted to meet the supply requirements of renewable hydrogen derived from water hydrolysis using renewable electricity.

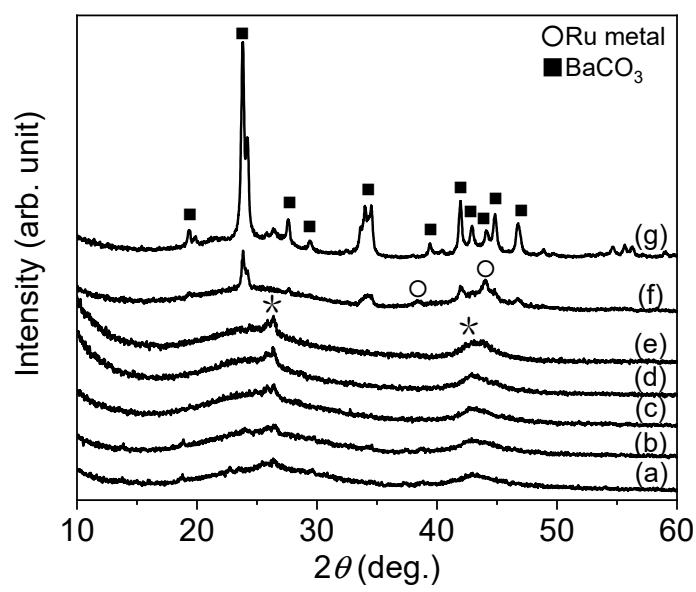

Figure 5. Wide-angle XRD patterns of the used Ba-Ru catalysts and reference materials-(a) $1.6 \mathrm{Ba}-10 \mathrm{Ru} / \mathrm{MPC}$, (b) $1 \mathrm{Ba}-10 \mathrm{Ru} / \mathrm{MPC}$ ，(c) $0.5 \mathrm{Ba}-10 \mathrm{Ru} / \mathrm{MPC，(d)} 0.1 \mathrm{Ba}-10 \mathrm{Ru} / \mathrm{MPC} ，(e) 10 \mathrm{Ru} / \mathrm{MPC}$ ，(f) $1.6 \mathrm{Ba}-10 \mathrm{Ru} / \mathrm{AC}$ ， and (g) 1.6Ba/MPC. The "asterisk" peaks arise from the carbon materials. 

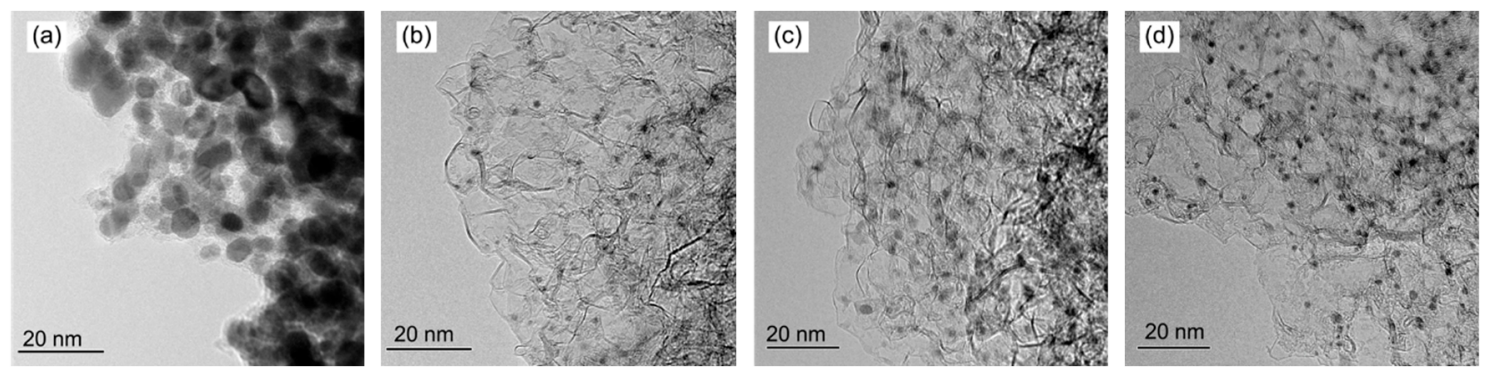
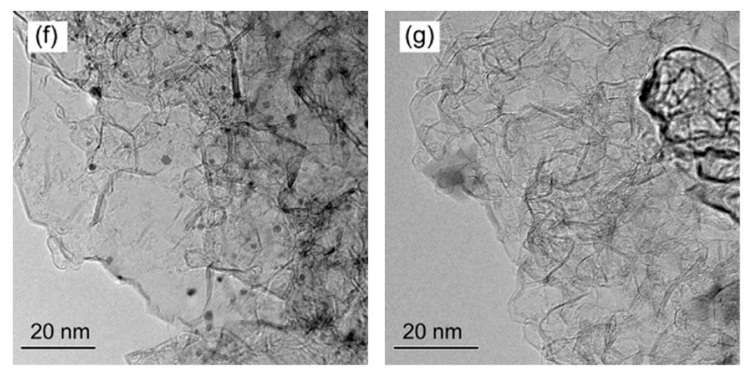

Figure 6. HRTEM images of the used Ba-Ru catalysts and reference materials: (a) 1.6Ba-10Ru/AC, (b) $1.6 \mathrm{Ba}-10 \mathrm{Ru} / \mathrm{MPC}$, (c) $1 \mathrm{Ba}-10 \mathrm{Ru} / \mathrm{MPC}$, (d) $0.5 \mathrm{Ba}-10 \mathrm{Ru} / \mathrm{MPC}$, (e) 0.1Ba-10Ru/MPC, (f) $10 \mathrm{Ru} / \mathrm{MPC}$, and $(\mathrm{g}) 1.6 \mathrm{Ba} / \mathrm{MPC}$.
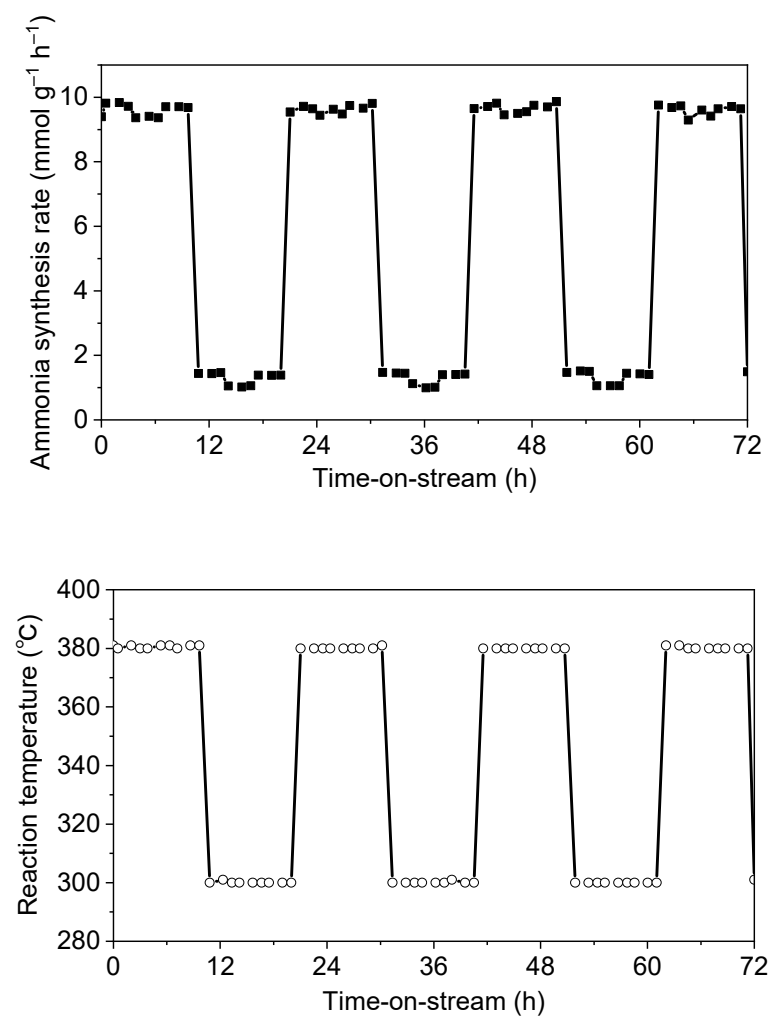

Figure 7. Cont. 


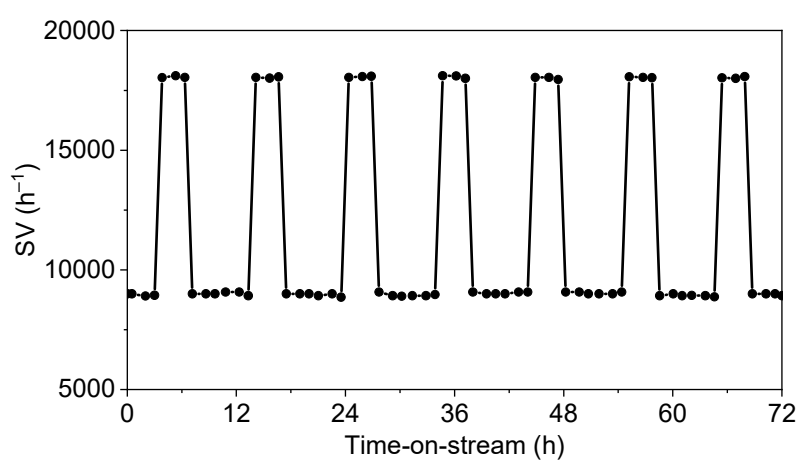

Figure 7. Dependence of the catalytic activity on reaction temperature and space velocity (SV) over the $1.6 \mathrm{Ba}-10 \mathrm{Ru} / \mathrm{MPC}$ for ammonia synthesis.

\section{Materials and Methods}

\subsection{Catalyst Preparation}

Commercial mesoporous carbon material (product code: $\mathrm{CNovel}^{\circledR} \mathrm{P}(3) 010,1500{ }^{\circ} \mathrm{C}$ annealing denoted as MPC) was supplied by Toyo Tanso Co., Ltd. (Osaka, Japan) and used as received. A microporous activated carbon (product code: HG15-119, denoted as AC) was obtained from Osaka Gas Chemical Co., Ltd., Osaka, Japan) and used after pretreatment at $500^{\circ} \mathrm{C}$ for $3 \mathrm{~h}$ in $\mathrm{H}_{2}\left(100 \mathrm{~mL} \mathrm{~min}{ }^{-1}\right)$. In a typical synthesis procedure, $1 \mathrm{~g}$ of MPC or AC support was dispersed in $70 \mathrm{~mL}$ of an ethanol-based impregnation solution $(50 \%, v / v)$, containing $0.31 \mathrm{~g}$ of nitrosylruthenium(III) nitrate $\left(\mathrm{Ru}(\mathrm{NO})\left(\mathrm{NO}_{3}\right)_{3}\right)$ (31.4 wt\% Ru; Mitsuwa Chemicals Co., Ltd., Osaka, Japan), and slowly evaporated at $70-80^{\circ} \mathrm{C}$. The dried solids were thermally treated at $400{ }^{\circ} \mathrm{C}$ for $3 \mathrm{~h}$ in $\mathrm{N}_{2}\left(\left(\right.\right.$ ramp rate $\left.=5{ }^{\circ} \mathrm{C} \mathrm{min}^{-1}\right)$, resulting in MPCand AC-impregnated Ru catalysts with Ru loading of $10 \mathrm{wt} \%$ (10Ru/MPC and 10Ru/AC, respectively) [21, 32]. Barium nitrate $\left(\mathrm{Ba}\left(\mathrm{NO}_{3}\right)_{2}, 0.41 \mathrm{~g}, 52.5 \mathrm{wt} \% \mathrm{Ba}\right.$; Wako Pure Chemical Industries Ltd., Osaka, Japan) was then impregnated into the $10 \mathrm{Ru} / \mathrm{MPC}$ and $10 \mathrm{Ru} / \mathrm{AC}$ samples using the aforementioned procedure except for the calcination step. Thus, the 1.6Ba-10Ru/MPC and 1.6Ba-10Ru/AC catalysts were obtained, where "1.6" represents a Ba/Ru molar ratio of 1.6 corresponding to $22 \mathrm{wt} \%$ Ba loading. For comparison, other reference catalysts including $0.1 \mathrm{Ba}-10 \mathrm{Ru} / \mathrm{MPC}, 0.5 \mathrm{Ba}-10 \mathrm{Ru} / \mathrm{MPC}$, and $1 \mathrm{Ba}-10 \mathrm{Ru} / \mathrm{MPC}$, were prepared using the aforementioned impregnation method. The 1.6Ba/MPC catalyst was prepared by impregnation of Ba into the MPC support with a Ba loading of $22 \mathrm{wt} \%$. The 0.1Ba-10Ru/MPC, $0.5 \mathrm{Ba}-10 \mathrm{Ru} / \mathrm{MPC}$, and $1 \mathrm{Ba}-10 \mathrm{Ru} / \mathrm{MPC}$ catalysts were prepared using the same procedure as that of the 1.6Ba-10Ru/MPC catalyst, except the Ba loading was reduced to $1.4,7$, and $14 \mathrm{wt} \%$, respectively.

\subsection{Characterization}

The specific surface area and porosity of the prepared catalysts were determined by $\mathrm{N}_{2}$ physisorption using a BELSORP-max instrument (MicrotracBEL Corp., Osaka, Japan) at $77 \mathrm{~K}$. The surface areas of the prepared samples were determined using the Brunauer-Emmet-Taylor (BET) equation while the micropore and mesopore volumes were calculated using the Dubinin-Astakhov (DA) plot or $\alpha_{s}$-plot method. The pore size distribution was obtained using the non-linear density function theory (NLDFT) method from the desorption isotherm using the slit-pore model. The compositions of the prepared catalysts were analyzed by elemental analysis (hydrogen, carbon and oxygen) and X-ray fluorescence. The crystallinity of the prepared catalysts was determined using a Rigaku MiniFlex600 diffractometer with $\mathrm{Cu} \mathrm{K} \alpha$ radiation $(\lambda=0.15418 \mathrm{~nm})$ operating at $40 \mathrm{kV}$ and $15 \mathrm{~mA}$. The $\mathrm{Ru}$ particle size and related size distribution were statistically analyzed via high-resolution transmission electron microscopy (HRTEM) using a TOPCON EM002B instrument operating at $120 \mathrm{kV}$. The Ru size distributions were calculated by counting more than 100 particles using a digital micrograph GMS 3 software (GATAN Inc., Pleasanton, CA, USA, 1996). The pulse chemisorption of CO was determined using an Ohkura Riken R6015 instrument. Freshly prepared samples were reduced under a $\mathrm{H}_{2}$ flow 


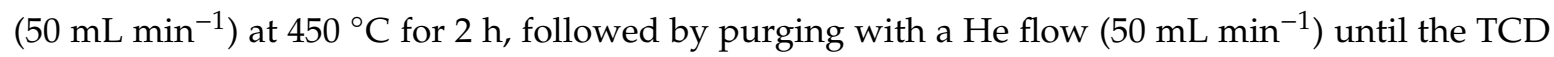
signal was stable at $50^{\circ} \mathrm{C}$. For the $\mathrm{CO}$ chemisorption, a sequential pulse using a standard gas of $10 \%$ $\mathrm{CO} / \mathrm{He}$ was introduced to the reduced samples at $50^{\circ} \mathrm{C}$ until no $\mathrm{CO}$ was adsorbed.

\subsection{Mild Ammonia Synthesis}

Ammonia synthesis over the prepared Ba-Ru catalysts was studied in a stainless steel fixed-bed reactor with a quartz inlet $\left(12 \mathrm{~mm}\right.$, internal diameter) under mild reaction conditions $\left(280-450{ }^{\circ} \mathrm{C}\right.$, $<1 \mathrm{MPa}$ ). It should be noted that the High Pressure Gas Safety Act of Japan has defined "high pressure gas" as equal to or higher than $1 \mathrm{MPa}$ at $35^{\circ} \mathrm{C}$. We specifically performed mild ammonia synthesis at the reaction pressure of $<1 \mathrm{MPa}$ using G1 grade $\mathrm{N}_{2}$ and $\mathrm{H}_{2}$ standard gases as feedstocks. The $\mathrm{H}_{2} / \mathrm{N}_{2}$ ratio in the feed gas was maintained at 3 . The prepared Ba-Ru catalysts were finely packed in the quartz inlet and placed in a stainless-steel cylindrical reactor, which was controlled by an automatic reaction test system (Taiyo system Corp., Japan). The Ba-Ru catalysts were reduced under a $\mathrm{H}_{2}$ flow (SV $=10000 \mathrm{~h}^{-1}$ ) at $450{ }^{\circ} \mathrm{C}$ for $2 \mathrm{~h}$ before ammonia synthesis. To start the reaction, hydrogen and nitrogen $\left(\mathrm{H}_{2} / \mathrm{N}_{2}\right.$ ratio $=3$ ) was fed to the fixed-bed reactor at $280-450{ }^{\circ} \mathrm{C}$ under a pressurized atmosphere. The stability test of the 1.6Ba-10Ru/MPC catalyst was performed for $>70 \mathrm{~h}$, where the reaction temperatures and SV were repeatedly and quickly changed in the ranges of $300-380{ }^{\circ} \mathrm{C}$ and in $9000-18000 \mathrm{~h}^{-1}$, respectively. The quantitative analysis of the downstream products was performed using a Shimadzu gas chromatograph (GC-2014) equipped with a TCD detector and a Thermon-3000 $+\mathrm{KOH}(2+2) \%$ Sunpak-N 60/100 mesh column (2.1 m length and $3.2 \mathrm{~mm}$ internal diameter, Shinwa Chemical Industries Ltd.). The ammonia synthesis rate was calculated by dividing the synthesized amount per unit time by the catalyst mass $\left(\mathrm{mmol} \mathrm{g}^{-1} \mathrm{~h}^{-1}\right)$.

\section{Conclusions}

Ba-promoted Ru nanoparticles supported on the mesoporous carbon materials with various $\mathrm{Ba} / \mathrm{Ru}$ ratios (0.1-1.6Ba-10Ru/MPC) were prepared by the impregnation method and tested under mild ammonia synthesis conditions. The influences of the $\mathrm{Ba} / \mathrm{Ru}$ ratio and mesoporous structure on the ammonia synthesis activity of the prepared $0.1-1.6 \mathrm{Ba}-10 \mathrm{Ru} / \mathrm{MPC}$ catalysts were studied and compared to those of reference catalysts. The as-made $0.1-1.6 \mathrm{Ba}-10 \mathrm{Ru} / \mathrm{MPC}$ catalysts contained $\mathrm{Ru}$ nanoparticles with sizes of approximately 1-2 $\mathrm{nm}$, independent of Ru loading, and small $\mathrm{Ba}\left(\mathrm{NO}_{3}\right)_{2}$ crystallites $(29-49 \mathrm{~nm})$ that increased in size with increasing Ba loading. In contrast, the 1.6Ba-10Ru/AC catalyst with similar $\mathrm{Ba}$ and $\mathrm{Ru}$ loadings contained large $\mathrm{Ba}\left(\mathrm{NO}_{3}\right)_{2}$ crystallites and small Ru nanoparticles on the pore mouths of microporous structure. The Ba size in $1.6 \mathrm{Ba} / \mathrm{MPC}$ was larger than that of $1.6 \mathrm{Ba}-10 \mathrm{Ru} / \mathrm{MPC}$, whereas the Ru sizes in $10 \mathrm{Ru} / \mathrm{MPC}$ and $1.6 \mathrm{Ba}-10 \mathrm{Ru} / \mathrm{MPC}$ were similar. In the catalytic study, all prepared 0.1-1.6Ba-10Ru/MPC catalysts were active towards ammonia synthesis, and their activities were much higher than that of the reference catalyst 1.6Ba-10Ru/AC. The 10Ru/MPC showed low activity for ammonia synthesis and the 1.6Ba/MPC sample without $\mathrm{Ru}$ showed no activity. The XRD, CO chemisorption, and HRTEM studies of the fresh and used catalysts showed that the 0.1-1.6Ba-10Ru/MPC catalysts contained small $\mathrm{BaO}_{x}$ species close to the surface of the metallic Ru particles as the catalytically active sites, which were able to catalyze mild ammonia synthesis efficiently, due to the synergistic effect of Ba and Ru. Moreover, these active sites were highly stable in the mesoporous structure and remained nearly unchanged after use. In contrast, the 1.6Ba-10Ru/AC catalyst with Ba and Ru on the outer surface of AC with a microporous structure was unstable for ammonia synthesis and serious aggregation of $\mathrm{Ba}$ and Ru was observed. The intermittently variable synthesis of ammonia using the $1.6 \mathrm{Ba}-10 \mathrm{Ru} / \mathrm{MPC}$ catalyst was performed in a fixed-bed reaction system under a $\mathrm{H}_{2}$ pressure of $0.99 \mathrm{MPa}$ for $>70 \mathrm{~h}$ by frequently varying the reaction temperatures and SV values. Although the ammonia synthesis activity varied depending on the reaction parameters, the 1.6Ba-10Ru/MPC catalyst showed high stability at all stages of intermittently variable synthesis of ammonia. Thus, it can be concluded that the 1.6Ba-10Ru/MPC catalyst has potential application 
for the synthesis of ammonia under mild and variable conditions, which can be supplied renewable hydrogen produced via water electrolysis and renewable energy as a sustainable production process.

Supplementary Materials: The following are available online at http://www.mdpi.com/2073-4344/9/5/480/s1, Figure S1: HRTEM images of the prepared Ba-Ru catalysts and reference materials: (a) 1.6Ba-10Ru/AC, (b) $1.6 \mathrm{Ba}-10 \mathrm{Ru} / \mathrm{MPC}$, (c) $1 \mathrm{Ba}-10 \mathrm{Ru} / \mathrm{MPC}, \quad$ (d) $0.5 \mathrm{Ba}-10 \mathrm{Ru} / \mathrm{MPC}, \quad$ (e) $0.1 \mathrm{Ba}-10 \mathrm{Ru} / \mathrm{MPC}$, (f) 10Ru/MPC, and (g) 1.6Ba/MPC., Figure S2: Ru size distributions of the prepared Ba-Ru catalysts: (a) 1.6Ba-10Ru/AC, and (b) 1.6Ba-10Ru/MPC., Figure S3: HAADF-STEM images of the fresh 1.6Ba-10Ru/MPC catalyst.

Author Contributions: M.N. designed and performed the experiments including the preparation and characterization of the catalysts and their catalyst activity tests and wrote the original paper; S.-Y.C. conceived of the characterization and catalytic tests of the prepared catalysts as well as reviewed and edited the paper; H.T. proposed and supervised the project. All the authors discussed and commented on the paper.

Funding: This research was funded by Japan Science and Technology Agency (JST), the Council for Science, Technology, and Innovation (CSTI), the Cross-ministerial Strategic Innovation Promotion Program (SIP), and the Energy Carriers program.

Acknowledgments: The authors acknowledge financial support from the Council for Science, Technology, and Innovation (CSTI), the Cross-ministerial Strategic Innovation Promotion Program (SIP), and the Energy Carriers program funded by Japan Science and Technology Agency (JST). Furthermore, the authors would like to express their gratitude to Akira Takatsuki of RIEF, AIST, for assisting with the HRTEM and HAADF-STEM measurements, Koji Kuramoto of RIEF, AIST, for assistance with XRD measurements, Takehisa Mochizuki of RIEF, AIST, for his help constructing the CO chemisorption instrument, and Kiyoaki Imoto of RIEF, AIST, for his help conducting mild ammonia synthesis. Special thanks to Editage (https://www.editage.jp/) for English language editing.

Conflicts of Interest: The authors declare no conflict of interest.

\section{References}

1. Fischer, H.; Meissner, K.J.; Mix, A.C.; Abram, N.J.; Austermann, J.; Brovkin, V.; Capron, E.; Colombaroli, D.; Daniau, A.L.; Dyez, K.A.; et al. Palaeoclimate constraints on the impact of $2{ }^{\circ} \mathrm{C}$ anthropogenic warming and beyond. Nat. Geosci. 2018, 11, 474-485. [CrossRef]

2. Ministry of the Environment. Outline of Long-term Low-carbon Vision. Available online: http://www.env. go.jp/press/103822/713.pdf (accessed on 11 July 2018).

3. Ministry of Economy, Trade and Industry. The Basic Hydrogen Strategy. Available online: http://www.meti. go.jp/english/press/2017/pdf/1226_003a.pdf (accessed on 6 August 2018).

4. He, T.; Pachfule, P.; Wu, H.; Xu, Q.; Chen, P. Hydrogen carriers. Nat. Rev. Mater. 2016, 1, 16059. [CrossRef]

5. Kurata, O.; Iki, N.; Matsunuma, T.; Inoue, T.; Tsujimura, T.; Furutani, H.; Kobayashi, H.; Hayakawa, A. Performances and emission characteristics of $\mathrm{NH}_{3}$-air and $\mathrm{NH}_{3}-\mathrm{CH}_{4}$-air combustion gas-turbine power generations. Proc. Combust. Inst. 2017, 36, 3351-3359. [CrossRef]

6. Smil, V. Detonator of the population explosion. Nature 1999, 400, 415. [CrossRef]

7. Schrock, R.R. Reduction of dinitrogen. Proc. Natl. Acad. Sci. USA 2006, 103, 17087. [CrossRef] [PubMed]

8. Faria, J.C.; Hendriks, C.A.; Blok, K. Carbon dioxide recovery from industrial processes. Energy Convers. Manag. 1995, 36, 827-830.

9. Cui, X.; Tang, C.; Liu, X.M.; Wang, C.; Ma, W.; Zhang, Q. Highly selective electrochemical reduction of dinitrogen to ammonia at ambient temperature and pressure over iron oxide catalysts. Chem. Eur. J. 2018, 24, 18494-18501. [PubMed]

10. Cui, X.; Tang, C.; Zhang, Q. A review of electrocatalytic reduction of dinitrogen to ammonia under ambient conditions. Adv. Energy Mater. 2018, 8, 1800369. [CrossRef]

11. McPherson, I.J.; Sudmeier, T.; Fellowes, J.; Tsang, S.C.E. Materials for electrochemical ammonia synthesis. Dalton Trans. 2019, 48, 1562-1568. [CrossRef]

12. Ozaki, A.; Aika, K.; Hori, H. A new catalyst system for ammonia synthesis. Bull. Chem. Soc. Jpn. 1971, 44, 3216. [CrossRef]

13. Raróg-Pilecka, W.; Miśkiewicz, E.; Szmigiel, D.; Kowalczyk, Z. Structure sensitivity of ammonia synthesis over promoted ruthenium catalysts supported on graphitised carbon. J. Catal. 2005, 231, 11-19. [CrossRef]

14. Raróg-Pilecka, W.; Miśkiewicz, E.; Jodzis, S.; Petryk, J.; Łomot, D.; Kaszkur, Z.; Karpiński, Z.; Kowalczyk, Z. Carbon-supported ruthenium catalysts for $\mathrm{NH}_{3}$ synthesis doped with caesium nitrate: Activation process, working state of Cs-Ru/C. J. Catal. 2006, 239, 313-325. [CrossRef] 
15. Kowalczyk, Z.; Jodzis, S.; Raróg, W.; Zielinski, J.; Pielaszek, J.; Presz, A. Carbon-supported ruthenium catalyst for the synthesis of ammonia. The effect of the carbon support and barium promoter on the performance. Appl. Catal. A Gen. 1999, 184, 95-102. [CrossRef]

16. Rossetti, I.; Pernicone, N.; Forni, L. Graphitised carbon as support for $\mathrm{Ru} / \mathrm{C}$ ammonia synthesis catalyst. Catal. Today 2005, 102-103, 219-224. [CrossRef]

17. Kitano, M.; Kanbara, S.; Inoue, Y.; Kuganathan, N.; Sushko, P.V.; Yokoyama, T.; Hara, M.; Hosono, H. Electride support boosts nitrogen dissociation over ruthenium catalyst and shifts the bottleneck in ammonia synthesis. Nat. Commun. 2015, 6, 6731. [CrossRef]

18. Kitano, M.; Inoue, Y.; Sasase, M.; Kishida, K.; Kobayashi, Y.; Nishiyama, K.; Tada, T.; Kawamura, S.; Yokoyama, T.; Hara, M.; et al. Self-organized ruthenium-barium core-shell nanoparticles on a mesoporous calcium amide matrix for efficient low-temperature ammonia synthesis. Angew. Chem. Int. Ed. 2018, 57, 2648-2652. [CrossRef] [PubMed]

19. Sato, K.; Imamura, K.; Kawano, Y.; Miyahara, S.; Yamamoto, T.; Matsumura, S.; Nagaoka, K. A low-crystalline ruthenium nano-layer supported on praseodymium oxide as an active catalyst for ammonia synthesis. Chem. Sci. 2017, 8, 674-679. [CrossRef]

20. Aika, K.; Takano, T.; Murata, S. Preparation and characterization of chlorine-free ruthenium catalysts and the promoter effect in ammonia synthesis. J. Catal. 1992, 136, 126-140. [CrossRef]

21. Nishi, M.; Chen, S.Y.; Takagi, H. A mesoporous carbon-supported and Cs-promoted Ru catalyst with enhanced activity and stability for sustainable ammonia synthesis. ChemCatChem 2018, 10, 3411-3414. [CrossRef]

22. Rodríguez-reinoso, F. The role of carbon materials in heterogeneous catalysis. Carbon 1998, 36, 159-175. [CrossRef]

23. Miyamoto, J.; Hattori, Y.; Noguchi, D.; Tanaka, H.; Ohba, T.; Utsumi, S.; Kanoh, H.; Kim, Y.A.; Muramatsu, H.; Hayashi, T.; et al. Efficient $\mathrm{H}_{2}$ adsorption by nanopores of high-purity double-walled carbon nanotubes. J. Am. Chem. Soc. 2006, 128, 12636-12637. [CrossRef]

24. Simon, P.; Gogotsi, Y. Materials for electrochemical capacitors. Nat. Commun. 2008, 7, 845-854. [CrossRef]

25. Aika, K.; Hori, H.; Ozaki, A. Activation of nitrogen by alkali metal promoted transition metal I. Ammonia synthesis over ruthenium promoted by alkali metal. J. Catal. 1972, 27, 424-431. [CrossRef]

26. Aika, K.; Kawahara, T.; Murata, S.; Onishi, T. Promoter effect of alkali metal oxides and alkali earth metal oxides on active carbon-supported ruthenium Catalyst for Ammonia Synthesis. Bull. Chem. Soc. Jpn. 1990, 63, 1221-1225. [CrossRef]

27. Rossetti, I.; Pernicone, N.; Forni, L. Promoters effect in $\mathrm{Ru} / \mathrm{C}$ ammonia synthesis catalyst. Appl. Catal. A Gen. 2001, 208, 271-278. [CrossRef]

28. Rossetti, I.; Mangiarini, F.; Forni, L. Promoters state and catalyst activation during ammonia synthesis over Ru/C. Appl. Catal. A Gen. 2007, 323, 219-225. [CrossRef]

29. Hansen, T.W.; Hansen, P.L.; Dahl, S.; Jacobsen, C.J.H. Support effect and active sites on promoted ruthenium catalysts for ammonia synthesis. Catal. Lett. 2002, 84, 7-12. [CrossRef]

30. Szmigiel, D.; Bielawa, H.; Kurtz, M.; Hinrichsen, O.; Muhler, M.; Raróg, W.; Jodzis, S.; Kowalczyk, Z.; Znak, L.; Zieliński, J. The kinetics of ammonia synthesis over ruthenium-based catalysts: The role of barium and cesium. J. Catal. 2002, 205, 205-212. [CrossRef]

31. Bielawa, H.; Hinrichsen, O.; Birkner, A.; Muhler, M. The Ammonia-synthesis catalyst of the next generation: barium-promoted oxide-supported ruthenium. Angew. Chem. Int. Ed. 2001, 40, 1061-1063. [CrossRef]

32. Nishi, M.; Chen, S.Y.; Takagi, H. Energy efficient and intermittently variable ammonia synthesis over mesoporous carbon-supported Cs-Ru nanocatalysts. Catalysts 2019, 9, 406. [CrossRef]

(C) 2019 by the authors. Licensee MDPI, Basel, Switzerland. This article is an open access article distributed under the terms and conditions of the Creative Commons Attribution (CC BY) license (http://creativecommons.org/licenses/by/4.0/). 